\title{
The relationship between the cervical spinal canal diameter and the pathological changes in the cervical spine
}

\author{
Yuichiro Morishita $\cdot$ Masatoshi Naito $\cdot$ \\ Henry Hymanson · Masashi Miyazaki • \\ Guizhong Wu $\cdot$ Jeffrey C. Wang
}

Received: 11 July 2008 / Revised: 5 February 2009/ Accepted: 24 March 2009/Published online: 9 April 2009

(C) The Author(s) 2009. This article is published with open access at Springerlink.com

\begin{abstract}
A congenitally narrow cervical spinal canal has been established as an important risk factor for the development of cervical spondylotic myelopathy. However, few reports have described the mechanism underlying this risk. In this study, we investigate the relationship between cervical spinal canal narrowing and pathological changes in the cervical spine using positional magnetic resonance imaging (MRI). Two hundred and ninety-five symptomatic patients underwent cervical MRI in the weight-bearing position with dynamic motion (flexion, neutral, and extension) of the cervical spine. The sagittal cervical spinal canal diameter and cervical segmental angular motion were measured and calculated. Each segment was assessed for the extent of intervertebral disc degeneration and cervical cord compression. Based on the sagittal canal diameter, the subjects were classified into three groups: A, subjects with a congenitally narrow canal, diameter of less than $13 \mathrm{~mm}$; $\mathrm{B}$, subjects with a normal canal, diameter of $13-15 \mathrm{~mm}$; $\mathrm{C}$, subjects with a wide canal, diameter of more than $15 \mathrm{~mm}$. When compared with Groups A and B, the disc degeneration grades at the C3-4, C5-6, and C6-7 segments
\end{abstract}

Y. Morishita - H. Hymanson - M. Miyazaki - G. Wu ·

J. C. Wang

Department of Orthopaedic Surgery,

University of California at Los Angeles,

Los Angeles, CA 90095, USA

M. Naito

Department of Orthopaedic Surgery, Fukuoka University,

Fukuoka, Japan

J. C. Wang $(\bowtie)$

UCLA Comprehensive Spine Center, 1250 16th Street,

Suite 745, Santa Monica, CA 90404, USA

e-mail: JWang@mednet.ucla.edu and the cervical cord compression scores at the C3-4 and C5-6 segments showed significant differences. Additionally, when compare with Groups A and C, the disc degeneration grades at all segments, except $\mathrm{C} 2-3$, and the cervical cord compression scores at all segments, except C2-3, showed significant differences. With respect to the cervical kinematics, few differences in the kinematics were observed between Groups B and C, however, the kinematics in Group A was different with other two groups. In Group A, the segmental mobility at the C4-5 and C6-7 segments were significantly higher than those observed in Group B, and the segmental mobility at the C3-4 segment was significantly lower than that observed in Groups B or C. We demonstrated the unique pathological and kinematic traits of cervical spine that exist in a congenitally narrow canal. We hypothesize that kinematic trait associated with a congenitally narrow canal may greatly contribute to pathological changes in the cervical spine. Our results suggest that cervical spinal canal diameter of less than $13 \mathrm{~mm}$ may be associated with an increased risk for development of pathological changes in cervical intervertebral discs. Subsequently, the presence of a congenitally narrow canal can expose individuals to a greater risk of developing cervical spinal stenosis.

Keywords A congenitally narrow canal - Cervical spine Intervertebral disc - Cervical spinal stenosis .

Positional MRI

\section{Introduction}

The size of the cervical spinal canal is clinically important in traumatic, degenerative, and inflammatory conditions. It is typically measured on plain radiographs as the 
developmental segmental sagittal diameter from the posterior surface of the vertebral body to the closest point on the spinolaminar line at the pedicle level. However, variations in magnification and the distance from the X-ray source to the film as well as from the subject to the film can confound these measurements. To avoid magnification variables with plain radiographs, Pavlov et al. [16] and Torg et al. [21] used the ratio of the sagittal diameter of the spinal canal to the sagittal diameter of the vertebral body obtained on plain radiographs. They found this method to be a reliable determinant of cervical spinal canal stenosis.

However, plain radiographs only have the ability to evaluate osseous structures, and soft-tissue abnormalities can also contribute to cervical spondylosis and cervical spinal canal stenosis. Compared with other radiological studies currently available to evaluate the spine, magnetic resonance imaging (MRI) provides the greatest range of information. MRI is routinely used for the evaluation of spinal degenerative disease due to its ability to accurately delineate soft-tissue structures such as intervertebral discs, spinal ligaments, or neural elements, and osseous structures such as vertebral bodies, spinal canals, the facet joints, or uncovertebral joints. The ability of MRI to detect subtle abnormalities in both soft-tissue and bone makes it highly sensitive for the detection of any pathology [22]; therefore, the functional cervical spinal canal or cervical spinal cord can be accurately measured using MRI.

There are numerous studies regarding the relationship between cervical spinal canal size and spinal cord conditions $[3,5-7,9-11,14,16,17,19-21]$. A congenitally narrow cervical spinal canal has been established as an important risk factor for the development of cervical spondylotic myelopathy (CSM) $[3,5,6,20]$. However, to the best of our knowledge, few reports thus far have described the mechanism underlying the increased risk of CSM in patients with a narrow cervical spinal canal. In this study, utilizing data describing cervical kinematics evaluated by positional MRI with dynamic motion of the cervical spine, we investigate the relationship between cervical spinal canal narrowing and pathological changes in the cervical spine.

\section{Materials and methods}

From February 2006 to May 2007, 295 symptomatic patients (135 men and 160 women) with an average age of 43.8 years (range 17-93 years) were examined with cervical MRI. For this study, consecutive patients experiencing neck pain with or without neurogenic symptoms were included. None of the subjects had previously undergone any spinal surgery. An Institutional Review Board approved this study.

\section{Positional MRI}

All patients underwent cervical MRI using a 0.6 Tesla MRI scanner (Upright Multi-Position ${ }^{\mathrm{TM}}$; Fonar Corporation, $\mathrm{NY}$ ) in the weight-bearing position with dynamic motions of the cervical spine, including flexion $\left(-40^{\circ}\right)$, neutral $\left(0^{\circ}\right)$, and extension $\left(20^{\circ}\right)$ postures. The imaging protocol included sagittal T1-weighted spin-echo sequences [repetition time (TR)/echo time (TE) $671 / 17 \mathrm{~ms}$, slice thickness $3.0 \mathrm{~mm}$, field of view $24 \mathrm{~cm}$, matrix $256 \times 200$, and number of excitations (NEX) 2] and T2-weighted fast spinecho sequences (TR/TE 3,432/160 ms, slice thickness $3.0 \mathrm{~mm}$, field of view $24 \mathrm{~cm}$, and NEX 2). All sequences were acquired without fat saturation.

The data obtained from the MR images were recorded on a computer for subsequent calculations, which were performed using an MRI analyzer. Sagittal MR images were analyzed in three positions-flexion, neutral, and extension. For digitization, 77 points were marked on the images by spine surgeons (C3-T1: six points on each vertebral body, two on each pedicle, and two on the spinal canal diameter at each intervertebral disc level, C2: one point on the tip of the odontoid process and six on the vertebral body, $\mathrm{C} 1$ : four points on the anterior, superior, and inferior surfaces of the anterior tubercle and the lower end of the spinous process, and the occiput (Oc): two points on the anterior and posterior baselines) (Fig. 1).

The sagittal angular motion $\left({ }^{\circ}\right)$ at five cervical intervertebral disc levels (C2-3, C3-4, C4-5, C5-6, and C6-7), and the sagittal diameter of the cervical cerebrospinal fluid

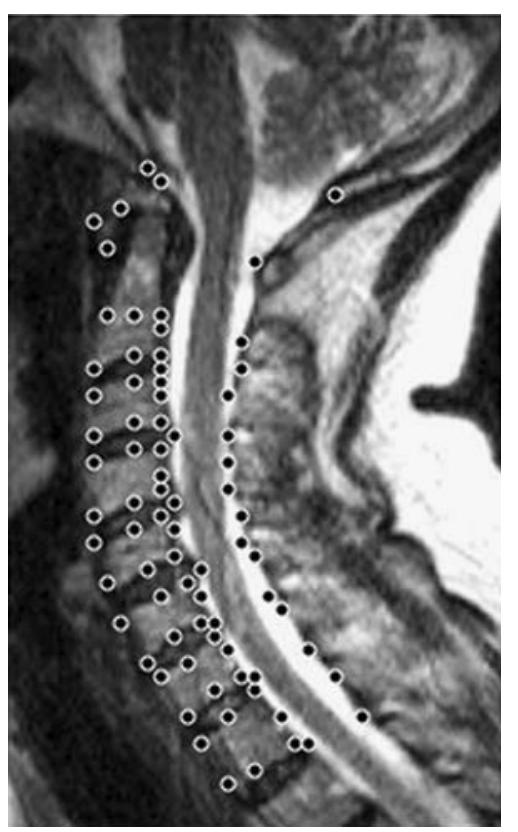

Fig. 1 Seventy-seven points were marked for digitization on the sagittal images 
(CSF) column (mm) at five pedicle levels (C3, C4, C5, C6, and $\mathrm{C7}$ ) were calculated. Based on the results of previous studies [7, 14, 17], we established the sagittal diameter of the cervical CSF column at a given pedicle level to be the sagittal diameter of the cervical spinal canal at that level.

\section{Cervical intervertebral discs}

A comprehensive grading system for cervical intervertebral disc degeneration was obtained through modification of previously reported systems of classification $[2,8,12,13$, 18]. Accordingly, neutral-position T2-weighted sagittal images of 1,475 cervical intervertebral discs corresponding to 295 subjects were classified into four grades (Table 1) by the primary author and were judged eligible for inclusion in the study.

\section{Cervical cord compression}

The extent of cervical cord compression at each segment was estimated by examining the neutral-position T2weighted sagittal images. Cervical cord compression was defined as the obliteration of the subarachnoid space resulting from compression due to disc herniation, osteophyte formation, or hypertrophy of the ligamentum flavum. Cervical cord compression at each segment was evaluated using a 3-point scale (range 0-2). A score of 0 indicated no cervical cord compression, a score of 1 indicated anterior or posterior cervical cord compression not affecting cord alignment, and a score of 2 indicated anterior or posterior cervical cord compression affecting cord alignment.

\section{Cervical mobility}

Total sagittal angular mobility of the cervical spine was defined as the absolute total value of the individual sagittal angular motions (C2-3 + C3-4 + C4-5 + C5-6 + C6-7) measured in degrees. The contribution of each individual segment to the total angular mobility of the cervical spine between flexion and extension was expressed as follows: percent segmental mobility $(\%)=($ sagittal angular motion of each segment in degrees)/(total sagittal angular motion in degrees) $\times 100$.
Total sagittal angular mobility $\left(^{\circ}\right)$ and percent segmental mobility $(\%)$ were evaluated for each group.

Cervical spinal canal sagittal diameter

The average sagittal diameter of the cervical spinal canal was defined as the average of the sagittal canal diameters at the pedicle level from C3 to C7. For the 295 subjects, the average canal diameter was $13.73 \pm 1.37 \mathrm{~mm}$. The subjects were classified into three groups based on their average sagittal canal diameter; Group A: subjects with a congenitally narrow canal, canal diameter of less than $13.0 \mathrm{~mm}$, Group B: subjects with a normal canal, canal diameter of 13.0-15.0 mm, Group C: subjects with a wide canal, canal diameter of more than $15.0 \mathrm{~mm}$.

All 295 subjects corresponding to three groups were used to evaluate pathological changes in the functional spinal units (FSUs). In addition, 120 subjects of the original 295 subjects were used to evaluate kinematics of the cervical spine. We excluded the subjects with severe intervertebral disc degeneration (i.e., grades 3 and 4) and severe cervical cord compression (i.e., compression score, more than 2) for evaluating cervical kinematics based on the findings of our previous study [13] which demonstrated that severe intervertebral disc degeneration and severe cord compression greatly affect cervical kinematics.

\section{Statistical analysis}

Student $t$ test was used for statistical analyses. A $P$ value of less than 0.05 was considered statistically significant.

\section{Results}

Pathological changes in FSUs

All 295 subjects were classified into three groups based on the average sagittal cervical spinal canal diameter: Group A consisted of 89 subjects with an average age of 45.1 years; Group B, 153 subjects with an average age of 43.7 years; Group C, 53 subjects with an average age of
Table 1 The grading system for cervical intervertebral disc degeneration

\begin{tabular}{llll}
\hline Grades & Nucleus signal intensity & Disc height & Structure of FSU \\
\hline 1 & Hyperintense & Normal & Without disc herniation \\
2 & Intermediate/hypointense & Normal/slight decrease & With/without disc herniation \\
3 & Hypointense & Decreased & With disc herniation/osteophyte \\
4 & Hypointense & Collapsed & With disc herniation/osteophyte \\
\hline
\end{tabular}


42.1 years. Subjects with narrower cervical spinal canal tended to be older, although no significant differences were observed among the groups.

Table 2 shows the grade of cervical intervertebral disc degeneration at all segments for each group. When the grades were compared between Groups A and B, the C3-4, C5-6, and C6-7 segments showed significant differences. When compared between Groups A and C, significant differences in the grades were observed at all segments except C2-3. In addition, when compared between Groups $\mathrm{B}$ and $\mathrm{C}$, a significant difference in the grades was only observed at the C5-6 segment.

Table 3 shows the score of cervical cord compression at all segments for each group. When the scores were compared between Groups A and B, the C3-4 and C5-6 segments showed significant differences. When compared between Groups $\mathrm{A}$ and $\mathrm{C}$, significant differences in the scores were observed at all segments except C2-3. In addition, when compared between Groups B and C, significant differences in the scores were observed at the $\mathrm{C} 4-5$, C5-6, and C6-7 segments.

\section{Cervical kinematics}

The 120 subjects were classified into three groups based on the average sagittal cervical spinal canal diameter: Group A consisted of 22 subjects with an average age of 37.6 years; Group B, 64 subjects with an average age of 38.6 years; and Group C, 34 subjects with an average age of 38.3 years. There were no significant differences in age among the groups.

Table 4 shows the sagittal cervical mobility at all segments for each group. The total angular mobility tended to be smaller with narrowing the sagittal cervical spinal canal diameter; however, no significant differences were observed among the groups.

With respect to percent segmental mobility in Group A, the C4-5 segment had the highest value, followed by the C6-7 or C5-6 segment. In Groups B and C, the C5-6 segment had the highest value, followed by the C4-5 segment. When the percent segmental mobility were compared between Groups A and B, the C3-4, C4-5, and C5-6 segments showed significant differences. When compared with Groups A and C, a significant difference in the percent segmental mobility was observed at the C3-4 segment. Additionally, when compared between Groups B and C, no significant differences in the percent segmental mobility were observed at all segments.

\section{Discussion}

Using 469 cadaver specimens, Lee et al. [11] reported that the average sagittal cervical canal diameter $(\mathrm{C} 3-\mathrm{C} 7)$ was $14.1 \pm 1.6 \mathrm{~mm}$, and that men had significantly larger diameters than women at all the levels. Direct measurements of skeletal specimens were used in their study in order to determine the spectrum of sagittal cervical spinal canal diameter. In the current study, we found the average sagittal canal diameter from $\mathrm{C} 3$ to $\mathrm{C} 7$ to be $13.73 \pm 1.37 \mathrm{~mm}$. Because our measurements were obtained using MRI, some soft-tissue structures might have influenced our results. We believe that our result regarding the sagittal diameter of the functional structure of the cervical spinal canal to be almost identical to that of Lee et al.
Table 2 The cervical intervertebral disc degeneration grades with each group

Compared with Groups A and $\mathrm{B}, \mathrm{B}$ and $\mathrm{C}$, and $\mathrm{A}$ and $\mathrm{C}$ $* P<0.05$, ** $P<0.01$, *** $P<0.001$

Table 3 The cervical cord compression scores with each group $\mathrm{B}, \mathrm{B}$ and $\mathrm{C}$, and $\mathrm{A}$ and $\mathrm{C}$

$* P<0.05$, ** $P<0.01$, *** $P<0.001$

\begin{tabular}{llllll}
\hline Groups & C2-3 & C3-4 & C4-5 & C5-6 & C6-7 \\
\hline A & $1.33 \pm 0.49$ & $1.96 \pm 0.71$ & $2.16 \pm 0.72$ & $2.67 \pm 0.89$ & $2.25 \pm 0.9$ \\
& & $*$ & & $*$ & $*$ \\
B & $1.4 \pm 0.52$ & $1.78 \pm 0.56$ & $2.01 \pm 0.71$ & $2.41 \pm 0.81$ & $1.97 \pm 0.85$ \\
& & & $*$ & \\
C & $1.38 \pm 0.49$ & $1.64 \pm 0.59$ & $1.85 \pm 0.69$ & $2.13 \pm 0.83$ & $1.77 \pm 0.95$ \\
& & $* *$ & $* *$ & $* * *$ & $* *$ \\
\hline
\end{tabular}

\begin{tabular}{llllll}
\hline Groups & C2-3 & C3-4 & C4-5 & C5-6 & C6-7 \\
\hline A & $0.03 \pm 0.18$ & $0.58 \pm 0.85$ & $0.57 \pm 0.85$ & $1.09 \pm 1.04$ & $0.49 \pm 0.77$ \\
& & $* * *$ & & $* * *$ & \\
B & $0.33 \pm 0.16$ & $0.21 \pm 0.55$ & $0.43 \pm 0.74$ & $0.63 \pm 0.74$ & $0.35 \pm 0.59$ \\
& & & $* *$ & $*$ & $* * *$ \\
C & 0 & $0.13 \pm 0.34$ & $0.17 \pm 0.47$ & $0.42 \pm 0.69$ & $0.11 \pm 0.32$ \\
& & $* * *$ & $* * *$ & $* * *$ & $* * *$ \\
\hline
\end{tabular}


Table 4 The sagittal mobility of the cervical spine with each group

\begin{tabular}{lllllll}
\hline Groups & \multicolumn{2}{l}{ Total $\left(^{\circ}\right)$} & \multicolumn{2}{l}{ Percent segmental mobility $(\%)$} & & \\
\cline { 3 - 7 } & & C2-3 & C3-4 & C4-5 & C5-6 & C6-7 \\
\hline A & $45 \pm 13.83$ & $13.47 \pm 7.39$ & $13 \pm 7.59$ & $28.91 \pm 11.92$ & $21.88 \pm 9.66$ & $*$ \\
& & & $* *$ & $*$ & $22.74 \pm 11.53$ \\
B & $46.58 \pm 13.41$ & $14.78 \pm 9.85$ & $20.74 \pm 11.39$ & $22.64 \pm 11.88$ & $23.69 \pm 12.39$ & $18.16 \pm 10.11$ \\
C & $48.41 \pm 12.52$ & $14.57 \pm 11.32$ & $18.34 \pm 11.39$ & $24.04 \pm 11.31$ & $24.33 \pm 14.38$ & $18.72 \pm 11.1$ \\
& & & $*$ & & & \\
\hline
\end{tabular}

Compared with Groups $\mathrm{A}$ and $\mathrm{B}, \mathrm{B}$ and $\mathrm{C}$, and $\mathrm{A}$ and $\mathrm{C} * P<0.05, * * P<0.01, * * * P<0.001$

Edward et al. [3] retrospectively reviewed the plain radiographs of 63 patients and determined that patients with a sagittal cervical spinal canal diameter of less than $10 \mathrm{~mm}$ had myelopathy, and that those with a diameter of $10-13 \mathrm{~mm}$ had premyelopathic changes. Additionally, **they found that patients with a diameter of 13-17 mm were less prone to myelopathy but was prone to symptomatic cervical spondylosis, and those with a diameter of greater than $17 \mathrm{~mm}$ were not prone to development of cervical spondylosis.

Moreover, the transverse area of the cord measured using MRI has been reported to have a strong correlation with the severity of myelopathy, postsurgical recovery of patients with cervical compressive myelopathy, and the pathological changes in the cord $[4,15]$. Additionally, Kuwazawa et al. $[9,10]$ demonstrated the dynamic effects of postural changes on the cervical cord using positional MRI.

The sagittal diameter of the spinal cord is nearly constant in adults averaging approximately $8 \mathrm{~mm}$ from C3 to C7 [1]. Therefore, patients with a congenitally narrow canal may be more susceptible to spinal cord compression with less pathological changes in the FSUs, i.e., herniated discs, osteophytic spurs, and hypertrophy of the ligamentum flavum or facet joints.

In our results, there were no significant differences among the groups with regards to age. When subjects with a normal and a wide canal were compared, the pathological changes in cervical intervertebral discs at all segments, except C5-6, were almost identical. However, when cervical cord compression was evaluated in subjects with a normal and a wide canal, the C4-5, C5-6, and C6-7 segments in subjects with a normal canal demonstrated significantly greater cervical cord compression than those observed in subjects with a wide canal. This may be due to the fact that subjects with a wide canal were able to better accommodate the cervical spinal cord, and therefore, the conditions of the spinal cords were less affected by the pathological changes in the FSUs. Additionally, when subjects with a congenitally narrow canal were compared with subjects with a wide canal, those with a congenitally narrow canal demonstrated significantly greater pathological changes in cervical intervertebral discs at all segments, except C2-3. Therefore, in subjects with a congenitally narrow canal, all segments, except C2-3, inevitably, demonstrated significantly greater cervical cord compression when compared to subjects with a wide canal. These results may affirm previous studies which stated that a congenitally narrow cervical spinal canal is an important risk factor for the development of cervical spinal canal stenosis $[3,5,6,20]$. In addition, our results suggest that a cervical spinal canal diameter of less than $13 \mathrm{~mm}$ was associated with an increased risk for development of pathological changes in cervical intervertebral discs. Initially, patients with a congenitally narrow canal may be exposed to an increased risk for development of pathological changes in cervical intervertebral discs. These same individuals may be subsequently exposed to a greater risk for development of cervical cord compression.

In the present study, we found that a congenitally narrow cervical spinal canal have differing effects on cervical kinematics. Few differences were observed in regard to the distribution of cervical segmental mobility between subjects with a normal and a wide canal, with the majority of segmental mobility occurring at the C5-6 segment, followed by the C4-5 segment. However, the distribution of cervical segmental mobility in subjects with a congenitally narrow canal was different than the distribution observed in subjects with a normal or a wide canal. In subjects with a narrow canal, the C4-5 segment contributed the most to cervical mobility, followed by the C6-7 or C5-6 segment. The segmental mobility at the C4-5 and C6-7 segments in subjects with a congenitally narrow canal were significantly higher than those observed within subjects with a normal canal. Contrarily, the segmental mobility at the C3-4 segment in subjects with a congenitally narrow canal was significantly lower than that observed within subjects with a normal or a wide canal. In subjects with a normal or a wide canal, segmental mobility steadily increased from C2-3 to $\mathrm{C} 5-6$. However, in subjects with a congenitally narrow canal, the segmental mobility was almost identical at the C2-3 and C3-4 segments, and then dramatically increased from C3-4 to C4-5. Additionally, in subjects with a 
congenitally narrow canal, the segmental mobility at the lower cervical segments (C4-5 to C6-7) contributed the majority of cervical mobility. These results suggest that subjects with a congenitally narrow canal may be exposed to a large mechanical loading at the lower cervical segments than subjects with a normal or a wide canal. This large mechanical loading at the lower segments may lead to early development of pathological changes in the lower cervical FSUs. We hypothesize that these kinematic differences associated with a congenitally narrow canal may greatly contribute to pathological changes in the cervical spine.

We believe that our findings allow clinicians to have a better understanding of the pathology associated with a congenitally narrow canal. Nevertheless, the current study does leave some issues unanswered. We demonstrated the unique pathological and kinematic traits that exist within a congenitally narrow canal. However, this kinematic observation within a congenitally narrow canal may not definitively explain the exact mechanisms underlying the pathological changes in the cervical spine. Therefore, using the current investigation as a pilot study, further research using a larger patient population may help further clarify the findings of this study, and elucidate the details regarding the relationship between sagittal cervical spinal canal diameter and the risk of CSM.

\section{Conclusions}

We demonstrated the unique pathological and kinematic traits of the cervical spine that exist within a congenitally narrow canal. We hypothesize that kinematic trait of the cervical spine associated with a congenitally narrow canal may greatly contribute to pathological changes in the cervical spine. Our results suggest that a cervical spinal canal diameter of less than $13 \mathrm{~mm}$ may be associated with an increased risk for development of pathological changes in cervical intervertebral discs. Subsequently, the presence of a congenitally narrow canal can expose individuals to a greater risk of developing cervical spinal stenosis.

Open Access This article is distributed under the terms of the Creative Commons Attribution Noncommercial License which permits any noncommercial use, distribution, and reproduction in any medium, provided the original author(s) and source are credited.

\section{References}

1. Anderson PA, Steinmetz MP, Eck JC (2006) Head and neck injuries in athletes. In: Spivak JM, Connolly PJ (eds) Orthopaedic Knowledge Update, Spine 3. AAOS 28:259-269
2. Benneker LM, Heini PF, Anderson SE, Alini M, Ito K (2005) Correlation of radiographic and MRI parameters to morphological and biochemical assessment of intervertebral disc degeneration. Eur Spine J 14:27-35. doi:10.1007/s00586-0040759-4

3. Edwards WC, LaRocca H (1983) The developmental segmental sagittal diameter of the cervical spinal canal in patients with cervical spondylosis. Spine 8:20-27. doi:10.1097/00007632198301000-00003

4. Fujiwara K, Fujimoto M, Owaki H, Kono J, Nakase T, Yonenobu K, Ochi T (1998) Cervical lesions related to the systemic progression in rheumatoid arthritis. Spine 23:2052-2056. doi: 10.1097/00007632-199810010-00003

5. Gore DR (2001) Roentgenographic findings in the cervical spine in asymptomatic persons: a ten-year follow-up. Spine 26:24632466. doi:10.1097/00007632-200111150-00013

6. Hayashi H, Okada K, Hamada M, Tada K, Ueno R (1997) Etiologic factors of myelopathy: a radiographic evaluation of the aging changes in the cervical spine. Clin Orthop Relat Res 214:200-209

7. Herzog RJ, Weins JJ, Dillingham MF, Sontag MJ (1991) Normal cervical spine morphometry and cervical spine stenosis in asymptomatic professional football players. Spine 16:178-186. doi:10.1097/00007632-199106001-00001

8. Kettler A, Rohlmann F, Neidlinger-Wilke C, Werner K, Claes L, Wilke HJ (2006) Validity and interobserver agreement of a new radiographic grading system for intervertebral disc degeneration: part 2. Cervical spine. Eur Spine J 15:732-741. doi:10.1007/ s00586-005-1037-9

9. Kuwazawa Y, Bashir W, Pope MH, Takahashi K, Smith FW (2006) Biomechanical aspects of the cervical cord: effects of postural changes in healthy volunteers using positional magnetic resonance imaging. J Spinal Disord Tech 19:348-352. doi: 10.1097/01.bsd.0000203273.90004.eb

10. Kuwazawa Y, Pope MH, Bashir W, Takahashi K, Smith FW (2006) The length of the cervical cord: effects of positional changes in healthy volunteers using positional magnetic resonance imaging. Spine 31:579-583. doi:10.1097/01.brs. 0000229228.62627 .75

11. Lee MJ, Cassinelli EH, Riew KD (2007) Prevalence of cervical spine stenosis: anatomic study in cadavers. J Bone Joint Surg Am 89:376-380. doi:10.2106/JBJS.F.00437

12. Luoma K, Vehmas T, Riihimaki H, Raininko R (2001) Disc height and signal intensity of the nucleus pulposus on magnetic resonance imaging as indicators of lumbar disc degeneration. Spine 26:680-686. doi:10.1097/00007632-200103150-00026

13. Morishita Y, Hida S, Miyazaki M, Hong SW, Zou J, Wei F, Naito M, Wang JC (2008) The effect of the degenerative changes in the functional spinal unit on the kinematics of the cervical spine. Spine 33:E178-E182

14. Okada Y, Ikata T, Katoh S, Yamada H (1994) Morphologic analysis of the cervical spinal cord, dura tube, and spinal canal by magnetic resonance imaging in normal adults and patients with cervical spondylotic myelopathy. Spine 19:2331-2335. doi: 10.1097/00007632-199405001-00019

15. Okada Y, Ikada T, Yamada H, Sakamoto R, Katoh S (1993) Magnetic resonance imaging study on the results of surgery for cervical compression myelopathy. Spine 18:2024-2029

16. Pavlov H, Torg JS, Robie B, Jahre C (1987) Cervical spinal stenosis: determination with vertebral body ratio method. Radiology 164:771-775

17. Payne E, Spillane J (1957) The cervical spine and anatomicopathological study of 70 specimens with particular reference to the problem of cervical spondylosis. Brain 80:571-596. doi: 10.1093/brain/80.4.571 
18. Pfirrmann CW, Metzdorf A, Zanetti M, Hodler J, Boos N (2001) Magnetic resonance classification of lumbar intervertebral disc degeneration. Spine 26:1873-1878. doi:10.1097/00007632200109010-00011

19. Prasad SS, O’Malley M, Caplan M, Shackleford IM, Pydisetty RK (2003) MRI measurements of the cervical spine and their correlation to Pavlov's ratio. Spine 28:1263-1268. doi: 10.1097/00007632-200306150-00009

20. Torg JS, Naranja RJ Jr, Pavlov H, Galinat BJ, Warren R, Stine RA (1996) The relationship of developmental narrowing of the cervical spinal canal to reversible and irreversible injury of the cervical spinal cord in football players. J Bone Joint Surg Am 78:1308-1314

21. Torg JS, Pavlov H, Genuario SE, Sennett B, Wisneski RJ, Robie BH, Jahre C (1986) Neurapraxia of the cervical spinal cord with transient quadriplegia. J Bone Joint Surg Am 68:1354-1370

22. Yu WD, Williams SL (2006) Spinal imaging: Radiographs, Computed tomography, and Magnetic resonance imaging. In: Spivak JM, Connolly PJ (eds) Orthopaedic Knowledge Update. Spine 3. AAOS 6:57-67 